\title{
O CANTO DA SEREIA. AMÉRICA LATINA PERANTE A ALCA
}

\author{
Sonia de Camargo
}

\begin{abstract}
Resumo: O objetivo é examinar o significado para os países latino-americanos em geral, e para o Brasil em particular, do projeto de formação da Alca proposto pelo governo norte-americano na Cúpula de Miami, em dezembro de 1994. Para tanto, faz-se uma reconstituição dos esquemas regionais de "nova geração" que emergiram no continente nos anos 90 , tomando como foco de análise o Nafta, ante-sala do que possa vir a ser a Alca, e o Mercosul.
\end{abstract}

Palavras-chave: regionalismos de nova geração; relações Estados Unidos/América Latina.

Abstract: This article examines the significance for Brazil in particular and for Latin America in general of the FTAA agreement proposed by the United States government at the Miami Summit in December of 1994. To this end, the author reviews the various regional frameworks of the "new generation" that emerged throughout the continent in the 1990's, taking as a starting point Nafta, which may provide a notion of what can be expected from the FTAA and Mercosul.

Key words: regionalisms of the new generation; U.S./Latin American relations.

A

Terceira Cúpula das Américas que se realizou em Quebec de 20 a 22 de abril de 2001 - precedida pela de Miami, em fins de 1994 e pela de Santiago, em 1998 - reuniu os 34 Chefes de Estado das três Américas, com exclusão de Cuba. O objetivo principal do encontro foi discutir o projeto de constituição de uma Área de Livre Comércio das Américas (Alca), cuja data de implantação, marcada para $1^{\circ}$ de janeiro de 2006, obteve, depois de algumas idas e vindas em relação a sua antecipação, consenso entre os países participantes. Contudo, a realização da "II Cúpula dos Povos", paralela à oficial, organizada por representantes de movimentos sociais do continente, e as manisfestações de rua em Quebec - cidade declarada zona militar durante três dias - e em outras cidades latino-americanas, mostrou ao Presidente George W. Bush que os assuntos hemisféricos estavam passando por um momento de extrema turbulência, maior do que há apenas alguns anos.

$\mathrm{Na}$ realidade, essas diferentes expressões de oposição ao projeto Alca são facilmente explicáveis se se levar em conta que grande parte dos países em desenvolvimento enfrentam, no presente momento, crises políticas e econômicas graves que fazem que, no seio de alguns de seus governos e, em especial, de suas sociedades, cresçam as restrições e as rejeições ao atual modelo econômico global e aos esquemas regionais nele inspirados, vistos como os principais geradores das vicissitudes sociais que os penalizam. No que se refere especificamente à América Latina, as maiores desconfianças e dúvidas concentramse nas políticas norte-americanas de segurança para a região e nos esforços para alcançar acordos de integração econômica e de abertura comercial no plano hemisférico.

E é justamente nesse contexto, em que se combinam, de forma contraditória, sentimentos e atitudes de adesão, realismo, pragmatismo, dúvida, rejeição, que as negociações dos países da região com os Estados Unidos para a formação de uma Área de Livre Comércio das Américas começam a adquirir um contorno mais definido, na esperança de que, para os que apostam no projeto, elas saiam do papel e se tornem, efetivamente, uma realidade concreta no prazo previsto e, para os que dele duvidam, que possam revertê-lo ou ajustá-lo aos objetivos e particularidades de cada nação. Partindo dessa perspectiva, e tomando como gancho as contradições apontadas, pode-se trazer para o debate alguns das principais linhas de conflito que, velhas ou novas, imaginárias ou reais, perturbam - 
neste momento em que as negociações para a implantação da Alca parecem avançar - as relações entre o norte e o sul das Américas.

Uma das razões mais evidentes para o desgaste dessas relações que, desde o início do governo do presidente George Bush pai e do fim da Guerra Fria até, aproximadamente, o fim dos anos 90, haviam sido mais cordiais que em qualquer outra época, é que a maioria dos países latino-americanos, como já assinalado, estão em pior situação do que há algum tempo. Com efeito, no começo dos anos 90, o otimismo coloria a região, onde a reforma econômica de cunho neoliberal produzia um aumento do crescimento e uma queda da inflação e onde a consolidação da democracia prometia mais justiça e maior segurança. Os dados da Cepal indicam que entre 1990 e 1997 a pobreza na região diminuíra de $41 \%$ para $36 \%$ e a indigência de $18 \%$ para $15 \%$ (Cepal, 1999). No entanto, em 1991, o lançamento da "Iniciativa para as Américas" que parecia abrir para a região a possibilidade de garantir o acesso por longo prazo ao mercado norte-americano e a entrada de maior volume de capitais produtivos, especialmente no caso dos países de menor desenvolvimento relativo - rendia aos Estados Unidos um voto de confiança (Hakim, 2001).

Entretanto, nos três últimos anos da década, a situação dos países da América Latina deteriora-se, com taxas de crescimento cada vez mais irregulares, quando não decrescentes em grande parte de seus países, e com a reversão da tendência anterior, produzindo-se um aumento do nível de pobreza e de exclusão social, com todas as suas conseqüências, como violência e criminalidade (E. Klein e V. Tokman, 2000). Como decorrência, embora a quase totalidade dos governos latino-americanos continuasse a apostar nas políticas de abertura dos mercados, ou por isso mesmo, a confiança por parte dos setores produtivos da região e de sua população em geral na capacidade de competir na economia globalizada sofreu um retrocesso, carregando em seu bojo a confiança irrestrita no ideário neoliberal preconizado pelos Estados Unidos.

Com efeito, a identificação desse país com as reformas reunidas no chamado "Consenso de Washington" que inclui além da abertura das economias, a privatização das empresas públicas e a desregulação das atividades financeiras, comerciais e dos mercados de trabalho - ao apresentarem resultados econômicos e sociais decepcionantes, fez que a liderança dos Estados Unidos no continente e seu poder real ou imaginado de dominar os organismos financeiros mundiais, como o FMI e o Banco
Mundial, fossem olhados com crescente desconfiança pela opinião pública. A esse conjunto de percepções se acrescentava a de que, enquanto a América Latina estava estancada economicamente, os Estados Unidos gozavam o período de auge econômico mais longo de sua história (Hakim, 2001).

Paralelamente às questões econômicas, o avanço da consolidação democrática na região parecia perder impulso em alguns países, desafiada pelo crescente cesarismo e corrupção do governo de Alberto Fujimori, no Peru, pela perda de controle institucional do governo eleito da Colômbia, fortemente golpeado pela guerra de guerrilhas e pelo acirramento da violência criminal, pelo golpe militar vitorioso no Equador, o primeiro na América Latina, nos últimos 24 anos, e por surtos antidemocráticos em outros países como Nicarágua, Guatemala, Paraguai (Le Monde Diplomatique, out. 2000). Logicamente essas turbulências político-institucionais não foram nem são imputadas diretamente aos Estados Unidos. Mesmo assim, algumas políticas do governo norte-americano para a região, como exemplarmente o "Plan Colômbia", em que estão previstos mecanismos de controle policial, fiscalização das fronteiras e uma ajuda militar imediata de 1.300 milhões de dólares, seguido da "Iniciativa Andina", para a qual está prevista uma ajuda financeira de aproximadamente 3.000 bilhões de dólares no curso de três anos - o que significa a militarização da luta antidrogas na região e sua internacionalização, com efeitos desestabilizadores para os demais países andinos - aumentaram as reticências das populações latino-americanas e de seus governos (Bonilla, 2001).

Partindo dessa perspectiva propõe-se, neste artigo, examinar as razões políticas e econômicas que impulsionaram o governo norte-americano a ampliar, nos anos 90, a agenda da política externa do seu país, incorporando nela a dimensão hemisférica. E as razões e o modo pelos quais, do ponto de vista latino-americano, especialmente dos países do Mercosul, o projeto Alca - visto por grande parte da região como inevitável - é introduzido, com prazo marcado para sua realização, nas agendas de sua política externa. Antes, porém, é oportuno abordar algumas considerações gerais sobre os acordos regionais que precederam o lançamento da proposta da integração hemisférica, ou melhor, sobre o surgimento, na América Latina, no início dos anos 90, de novas modalidades de regionalismos, os chamados "sistemas continentais de nova geração", cuja lógica e objetivos diferem, em muitos aspectos, dos da geração dos anos 60 (Hurrel, 1995). Como exemplos mais 
significativos pode-se citar o Mercado Comum do Sul (Mercosul), constituído pelo Tratado de Assunção, em março de 1991, a Iniciativa para as Américas, lançada pelo presidente George Bush, em junho do mesmo ano, o Acordo de Livre Comércio da América do Norte (Nafta), implantado em janeiro de 1994, e a proposta de formação de uma Área de Livre Comércio das Américas (Alca), apresentada em dezembro do mesmo ano.

\section{REGIONALISMOS DOS ANOS 90}

Esta análise inicia-se salientando que a formação de blocos regionais está diretamente ligada à configuração geopolítica e geoeconômica do sistema global no qual estão inseridos. Ou, em outras palavras, que a emergência desses blocos econômicos traduzem as transformações espaciais e os processos de desterritorialização e reterritorialização do atual sistema-mundo, ambos movimentos fundamentados na lógica capitalista da competição global. Na realidade os fenômenos da globalização e da regionalização, superpostos e interligados, expressam formas de acumulação do capital e formas de distribuição do poder que reorganizam espacialmente a economia e a política no plano mundial. E essa reorganização do capitalismo, atestada pela hipermobilidade do capital e pela cessão de autonomia política que se transfere para o emergente sistema comandado pelas grandes corporações, revestese de um número de fenômenos e de configurações analiticamente distintos, unificados pela emergência de um princípio organizativo novo, suficientemente estável para definir os contornos de uma nova ordem mundial, pelo menos por um determinado tempo (Marshall, 1998).

Nesse contexto, a globalização - ao redefinir o locus do poder político, ampliando-o para fora dos governos soberanos por meio de sua concentração nas grandes corporações transnacionais, e ao reorganizar a atividade econômica, passando-a do plano nacional para a regional e global - põe os estados nacionais diante de um impasse e de um desafio. Com efeito, a lógica neoliberal que preside o atual processo de globalização, ao ter como utopia a criação de um mercado global livre de controles sociais e políticos, põe em questão a habilidade do atual sistema de Estados para enfrentar alguns dos principais problemas e desafios de natureza transnacional (Mittelman, 2001).

Contudo, é preciso considerar o fato de que a própria globalização da economia força as atividades das empresas transnacionais de qualquer país a se tornarem mais depen- dentes da boa vontade do país em que operam. Dessa maneira, os Estados, com suas diferentes competências, continuam inevitavelmente a participar no processo capitalista em sua atual fase de acumulação. Isso, contudo, não invalida que tenham de enfrentar o "paradoxo global", de que nos fala Naisbaitt (1994), isto é, que tenham que se mover e barganhar entre o impulso voltado para a consolidação e ampliação dos interesses nacionais, de um lado, e a promoção da mobilidade do capital, de outro (Marshall, 1998).

É essa a lógica que fundamenta e justifica os atuais "esquemas regionais de nova geração". Na realidade, a emergência de um princípio novo de organização mundial torna a opção regional um meio considerado eficaz de administrar com mais facilidade o paradoxo global referido. Se adotarmos o ponto de vista dos Estados de menor desenvolvimento relativo que avaliam que a expansão das oportunidades de mercados aumenta, paralelamente, às exigências de competitividade, vemos que essa opção está vinculada ao fato de que os regimes de integração subregional significam uma forma de aprendizado e uma ponte que facilita e abre caminho para transações internacionais mais amplas, permitindo-lhes alcançar, de forma mais competitiva, novos patamares em seu processo de inserção na economia internacional. Com efeito, ao incorporarem no âmbito da região modos de articulação da economia política global e, ao mesmo tempo, modos de ação política antes reservados aos espaços nacionais, adquirem maiores recursos econômicos e político-institucionais para administrarem, coletivamente, as exigências de ajuste das economias dos países-membros e assegurarem melhores condições de competirem em mercados globais, preservando, ao mesmo tempo, características e interesses próprios da região, em seu conjunto (Camargo, 1997).

No que se refere aos Estados mais fortes, os esquemas de integração regional, quando formados por sócios acentuadamente assimétricos, podem ser percebidos por eles e por seus agentes econômicos como significativamente favoráveis a seus interesses, uma vez que avaliam que os avanços cada vez mais rápidos nos meios de comunicação e de transporte e a erosão da autonomia política dos governos com quem se associaram, permitem a seus capitais atravessarem fronteiras com crescente liberdade, e a seus produtos invadirem mercados em espaços cada vez mais amplos, abertos e desregulados (Camargo, 1997).

Paralelamente, ou melhor, interligados aos fatores examinados, os blocos econômicos respondem, igualmente, aos interesses político-estratégicos, em especial no caso dos países centrais, que buscam não apenas assegurar o 
nível de riqueza que desejam preservar ou alcançar mas, sobretudo, defender, fortalecer e ampliar a posição relativa de poder que ocupam no cenário mundial. Nessa perspectiva, a economia torna-se uma questão de segurança, tornando as relações entre forças econômicas e atuação política externa extremamente complexas e difusas. No caso específico dos Estados Unidos - potência hegemônica do capitalismo atual e, portanto, a única com interesses globais - o fim da guerra fria proporcionou a essas duas dimensões, a econômico-comercial e a de segurança, um mesmo nível de prioridade. Isso significa que o desafio maior para o governo norte-americano é conduzir o país ao cume da economia mundial, dissipando ao mesmo tempo os ressentimentos provocados por sua posição hegemônica, e convencer os demais países de que a reorganização da ordem mundial se dá tanto em seu próprio benefício como na dos demais países. Já no caso dos países não situados no centro do sistema, os esquemas de integração econômica, quando apoiados regionalmente em objetivos, políticas e instituições comuns têm, além dos fins econômico-comerciais previstos explicitamente, objetivos políticos, de modo que a região adquira a possibilidade de falar com uma voz única nas negociações internacionais. Isso, por sua vez, lhes dá maior poder para defenderem interesses regionais próprios e de seus países, assim como políticas e ações que se referem a toda a humanidade.

É, portanto, com base nessa lógica e dentro de um novo quadro de tensões e desafios, que antigos esquemas regionais reestruturaram-se em diversas partes do mundo, outros foram criados, apresentando diferentes modelos institucionais, objetivos e campos de atuação. No que se refere aos países da América Latina, que se encontram, neste começo de século, imersos em uma economia global que não os favorece, a perspectiva de se integrarem com vizinhos regionais mostra-se como o caminho mais curto e promissor. Esse caminho passa, para alguns, pelos processos sub-regionais ou continentais de integração, como a Comunidade Andina, o Mercosul, a Comunidade do Caribe, o Mercado Comum Centro Americano, a Área de Livre Comércio da América do Norte ou o projeto de integração sul-americana, para outros pelo grande projeto de integração hemisférica que, lançado e liderado pelos Estados Unidos, atrai, preocupa e amedronta a região.

Levando em conta essa multiplicidade de acordos, projetos e propostas regionais, e considerando os fins específicos deste trabalho, inicialmente, irá se analisar a Área de Livre Comércio da América do Norte (Nafta) uma vez que, constituindo-se como a ante-sala da futura integra- ção hemisférica, é uma referência obrigatória para a reflexão em questão. Em seguida abordar-se-á o Mercosul, especificamente em sua função de interlocutor privilegiado com os Estados Unidos, no contexto das negociações referentes à formação da Área de Livre Comércio das Américas. Esses dois temas levam, naturalmente, a reconstituir os passos que pavimentaram a história recente da América Latina em seu entrelaçamento com a grande potência, ao mesmo tempo regional e mundial, passos que, segundo algumas vozes latino-americanas, conduzem o continente, inexoravelmente, na direção de uma integração de alcance hemisférico.

\section{O DESTINO DAS AMÉRICAS}

\section{Área de Livre Comércio da América do Norte}

Do ponto de vista geral latino-americano, e brasileiro em particular, seria possível afirmar que a presença da Alca como projeto a médio e longo prazo e a do Mercosul, como uma realidade imediata que parece estar perdendo fôlego - ao lado nas negociações com a União Européia para a constitução de um acordo de livre-comércio - ocupam, quase que em tempo integral, os corações e as mentes, as agendas dos governos, as diplomacias e os agentes econômicos dos países latino-americanas.

Analisar esses dois temas implica, necessariamente, trazer para o centro do debate as relações "perigosas" da região com os Estados Unidos, já que a possibilidade de realização de um projeto de integração hemisférica - que tem em uma ponta a potência hegemônica mundial e, na outra, países de menor nível de desenvolvimento e de poder - coloca questões que, não só ameaçam a própria continuidade dos esquemas sub-regionais, como despertam desconfianças e dúvidas em seus membros potenciais.

Tomando-se como ponto de partida o início dos anos 90, principia-se a análise pela "Iniciativa para as Américas", proposta lançada pelo então presidente norte-americano George Bush em junho de 1991, num contexto em que as relações entre os países latino-americanos e os Estados Unidos haviam começado a se tornar mais cordiais e cooperativas do que haviam sido em tempos imediatamente anteriores. Algumas razões explicam o relativo otimismo daquele momento, entre as quais a redemocratização dos sistemas políticos da região e a perspectiva de adoção de políticas econômicas neoliberais que se mostraram inicialmente exitosas na maior parte de seus países (Hakim, 2001). 
Dentro desse contexto, a "Iniciativa para as Américas" expôs, pela primeira vez, a possibilidade de um acordo de cooperação econômico-comercial entre países do primeiro e do terceiro mundos, proposta com a qual o governo dos Estados Unidos pretendia preencher um vazio em suas relações com os países latino-americanos que haviam sido perturbadas, nos anos 80 , por temas conflitivos como o da dívida externa, a questão da América Central e a do tráfico de drogas, estabelecendo um diálogo mais construtivo com o subcontinente (Hakim, 1992).

Alguns desses temas já haviam sido negociados anteriormente pelo próprio Presidente Bush no início de seu mandato, como a questão da dívida externa, cujo Plano Brady representou algum alívio para os países devedores, especialmente no âmbito dos acordos com o México e a Costa Rica. Da mesma maneira, a solução parcial de outras questões, como a da América Central, já havia sido obtida, tendo os Estados Unidos alcançado alguns de seus principais objetivos, como a expulsão do poder do Gen. Noriega, no Panamá, a derrota do governo Sandinista, na Nicarágua, e a perspectiva de um acordo negociado em El Salvador (Garcia, 1998). Esses resultados, aliando-se ao fato de que o componente comercial do projeto abria a possibilidade para que as economias latino-americanas acedessem ao crescente mercado norte-americano por meio da formação de áreas de livre-comércio sub-regionais compatíveis com os esquemas multilaterais, contribuíram para que a Iniciativa para as Américas, sobretudo em uma conjuntura em que os resultados da Rodada Uruguai pareciam incertos, tivesse uma boa receptividade por parte dos países da América Latina (Fritsch, 1992).

Na realidade, a Iniciativa para as Américas apresentava um caráter mais político do que econômico, uma vez que não se tratava de reorientar a política comercial norte-americana, nem de propor a transferência de recursos substanciais para a região, dados os próprios limites orçamentários do país, mas de recuperar o diálogo político com a América Latina que, depois de 1961, quando havia sido lançada a Aliança para o Progresso, fora perdendo importância. Várias considerações por parte da Casa Branca impulsionaram esta nova tentativa de formular uma política interamericana, entre as quais a idéia de que a crise econômica latino-americana poderia ter um impacto negativo sobre os processos de democratização na região e sobre o tráfico de drogas em todo o continente.

Ao mesmo tempo, a Iniciativa para as Américas era vista por Washington como um meio de reforçar a tendência crescente na direção da liberalização da economia e da abertura dos mercados, o que levou o governo norte-americano a fortalecer a posição dos líderes regionais comprometidos com esse tipo de política e a incentivar os indecisos, introduzindo ao mesmo tempo a idéia de uma possível integração econômica com os Estados Unidos (Hakim, 1992).

Aproximadamente três anos depois do lançamento da Iniciativa para as Américas, em janeiro de 1994, na administração do Presidente Clinton, um novo passo é dado no sentido de estabelecer uma efetiva integração comercial com um país em desenvolvimento com quem fazia fronteira, o México, empreendimento que tomou a forma de uma Área de Livre Comércio da América do Norte entre esse país, o Canadá e os Estados Unidos (Nafta) que abriu o caminho para que, em dezembro de 1994, no âmbito da cúpula de Miami, o governo norte-americano lançasse formalmente a proposta de criação de uma Área de Livre Comércio das Américas.

Dessa maneira, em termos substantivos, o Nafta, implantado em janeiro de 1994, concretizou a idéia de que um único regime continental de acumulação, que ocuparia a área que se estende da fronteira da Guatemala ao Pólo Norte, deveria sobrepor-se às três economias separadas. Em termos instrumentais, significou um mecanismo destinado a criar normas que assegurassem mobilidade e eficiência para os agentes econômicos, leia-se corporações transnacionais, para não dizer norte-americanas, que transitavam livremente por meio de duas fronteiras nacionais, e regras de origem que os protegessem contra a competição extra-regional (Clarkson, 2000).

No que se refere, especificamente, aos interesses imediatos dos Estados Unidos, o Nafta surgiu como um complemento ou uma alternativa às negociações multilaterais que se realizavam no âmbito do que era então o GATT, cuja rodada Uruguai não parecia saber adaptar-se às novas condições do comércio mundial. Se, nos anos anteriores, o GATT fora dominado pelos países centrais que negociavam entre si reduções tarifárias para produtos de seu interesse, nos anos 90 dificuldades entre esses próprios países - como a resistência da Comunidade Européia em liberalizar sua Política Agrícola Comum e do Japão em abrir seus mercados às exportações norte-americanas - deram munição para que os Estados Unidos tentassem formar um bloco comercial próprio no Hemisfério Ocidental e, paralelamente, pregar para o resto do mundo a integração global dos mercados, em toda sua plenitude.

Quanto ao México, a idéia de participar de um processo de negociação com o "poder imperial" e de desenvol- 
ver, formalmente, laços comerciais mais estreitos com ele, teria parecido impossível algumas décadas antes. Entretanto, no início dos anos 90, seguindo a tendência dos demais países latino-americanos e caribenhos que começavam a reduzir unilateralmente suas tarifas externas e a abrir seus mercados, o presidente Carlos Salinas de Gortari faz um pedido oficial para que se iniciassem as conversações referentes à incorporação do país ao acordo de livre-comércio. É verdade que o terreno já havia sido preparado anteriormente pela estratégia de liberalização econômica lançada em 1985 pelo presidente De La Madrid, momento em que o México toma a decisão de incorporar-se ao CATT e de assinar um número significativo de acordos bilaterais com os Estados Unidos que abrem caminho para negociações futuras mais amplas (Lustig, 1992).

Cabe destacar que a decisão do México de institucionalizar os vínculos comerciais com os Estados Unidos apoiou-se em uma situação concreta já existente, a de uma relação comercial em que mais de $80 \%$ das exportações mexicanas dirigiam-se ao mercado norte-americano e perto de $70 \%$ eram precedentes desse país, dando, assim, aos Estados Unidos o lugar de primeiro parceiro comercial. Em sentido inverso, o México representava, para os Estados Unidos, o seu terceiro maior mercado exportador e importador.

Contudo, a aparente consistência das razões econômico-comerciais que justificavam a prioridade do projeto Nafta para os Estados Unidos e para o México, não impediu o surgimento de temores, restrições e resistências, de diferentes procedências, matizes e alcance, de acordo com o país e o setor social de onde provinham. No que se refere aos Estados Unidos, a resistência, pelo lado da esquerda, vinha, essencialmente, dos movimentos trabalhistas, ambientalistas, ativistas de direitos humanos e de seus representantes Democratas, e pela direita, dos Republicanos nacionalistas. Contudo, apesar de a forte mobilização contra o Nafta, estes setores foram derrotados no Congresso, em que as forças empresariais representadas pelos Republicanos e parte dos Democratas conservadores moderados, apoiadas pelo próprio presidente Clinton, conseguiram aprovar o projeto, obtendo na Câmara 234 votos contra 200 e no Senado 61 contra 38 (Shoch, 2000). Na verdade, o processo de aprovação foi bastante trabalhoso, especialmente pelo fato de que, desde 1993, não vigorava mais o sistema de "autoridade de promoção comercial" (fast track) que dava ao Executivo a possibilidade de negociar os acordos comerciais sem estar sujeito a possíveis emendas do Congresso. Sem ele, o Executivo teve de negociar votos, um a um, com membros individuais ou com grupos no Congresso.

$\mathrm{O}$ argumento dos que se opunham ao projeto, especificamente dos trabalhadores organizados reunidos na grande Central Sindical AFL-CIO, era a possibilidade de perda de fontes de trabalho. Seus membros argumentavam que, em razão da grande diferença salarial entre os trabalhadores mexicanos e os de seu país, haveria um deslocamento destes que seriam substituídos pela mão-de-obra barata vinda do México para os Estados Unidos, num contexto de pouca ou baixa efetividade institucional que pudesse neutralizar os custos da transição. Já no caso do México, os temores e resistências dos setores sociais concentraram-se, especialmente, na mudança da estrutura do emprego e do regime da terra com seu conseqüente impacto sobre os salários reais, sobre a flexibilização do trabalho, e sobre a diminuição das medidas de proteção aos trabalhadores e aumento de sua mobilidade. No que se refere especificamente à mudança do regime da terra, $\mathrm{o}$ deslocamento do campo para a cidade atingiu, em especial, os produtores agrícolas mexicanos vinculados à produção de grãos. Com efeito o campo mexicano, que já passara anteriormente por uma reforma em sua legislação de propriedade da terra em razão de sua privatização, viu surgir, graças à liberalização comercial dos bens agrícolas, um amplo fluxo de migração que, sem proteção e sem alternativas de fontes de trabalho, abandonou as áreas rurais, procurando as cidades, tanto no México como nos Estados Unidos.

Ao lado dessas questões, a crise financeira mexicana de fins de 1994 - que surpreendeu o próprio governo norte-americano - e sua crise política em que não faltaram os ingredientes de corrupção e violência física, como o assassinato de Colosio, candidato à presidência, e de Ruiz Massieu, Secretário-Geral do PRI, e as revoltas constantes da população camponesa, em que se inclui o levantamento armado de Chiapas, em janeiro de 1994, representaram um bom termômetro da situação em que se deu a implantação do Nafta (Morris e Passe-Smith, 2001).

Agora que se passaram sete anos, é difícil fazer, e a intenção não é essa, uma avaliação dos resultados da opção mexicana de participar do regime continental. Apenas convém destacar que, em virtude da proximidade geográfica e sua forte dependência da economia norte-americana, a desaceleração econômica desse país está atingindo seriamente o crescimento industrial do México e seu mercado de trabalho. Segundo as notícias mais recentes, fábricas estrangeiras que haviam atravessado a fron- 
teira mexicana para beneficiar-se de sua mão-de-obra barata, iniciaram um processo de demissão de dezenas de milhares de trabalhadores, revertendo uma tendência de expansão do mercado de trabalho decorrente de um crescimento econômico significativo na esteira do acordo Nafta.

Um último tópico a ser examinado, o das regras e normas vigentes no acordo Nafta. Foi por meio do slogan do "comércio livre" que o sistema político mexicano, que contava com forte presença do Estado, foi reestruturado à luz das necessidades de liberdade das corporações transnacionais norte-americanas postas em face das crescentes pressões por competitividade no contexto de uma ordem globalizada. Na realidade o acordo Nafta, especificamente em seu Capítulo 11, inclui um conjunto de novos direitos e proteções para os investimentos das empresas, sem precedente conforme extensão e poder. $\mathrm{O}$ artigo 1.110, por exemplo, garante aos investidores estrangeiros, por meio de um sistema de arbitragem, uma compensação por qualquer tipo de expropriação direta (nacionalização) ou que possa ser vista como indireta, ainda que perfeitamente legal, determinada pelo governo de um dos países integrantes do Nafta. Da mesma maneira, garante compensação se um investidor estrangeiro considerar que os rendimentos de seu capital aplicados na região, ou mesmo rendimentos futuros potenciais, tenham sido prejudicados por ações dos governos locais. O sistema de arbitragem funciona do seguinte modo: o investidor estrangeiro pode iniciar um processo arbitral por perdas monetárias presentes ou potenciais diante de um tribunal fechado para a observação e participação públicas e que não oferece nenhuma das garantias básicas asseguradas nas cortes nacionais. Por conseguinte, as empresas estrangeiras que operam em um dos países do Nafta têm mais direitos que empresas domésticas que operam em seu próprio país, o que significa segurança e liberdade em toda a extensão do continente, o que implica maior flexibilidade e mobilidade. A diferença fundamental deste artigo com o de outros acordos comerciais é que as corporações globais são livres para pleitear por conta própria sem precisar da aprovação dos governos nacionais para agir em seu próprio benefício em fóruns internacionais (Greider, 2001). É interessante lembrar que o Capítulo 11 do Nafta baseouse no "acordo multilateral de investimento", no qual a maioria dos países da Organização Mundial do Comércio rejeitara há alguns anos por considerá-lo um ultrajante e desrespeito à soberania nacional (Bottary e Swenarchuck, 2001).

\section{Área de Livre Comércio das Américas}

O tema Nafta leva diretamente à Alca uma vez que este projeto de integração das duas metades do hemisfério constitui uma ampliação, para as três Américas, da lógica e das regras, procedimentos e políticas desenvolvidas no âmbito do acordo entre Estados Unidos, Canadá e México.

No que se refere à conjuntura internacional, as condições que haviam levado à implantação do Nafta mostravam-se igualmente favoráveis para o lançamento de um projeto mais ambicioso e abrangente que deveria cobrir todo o hemisfério. Com efeito, a consolidação dos Estados Unidos como única potência global, o avanço rápido do processo de globalização financeira que aumentara o peso estratégico do campo econômico na política mundial, a expansão ideológica da democracia liberal e do capitalismo desterritorializado, permitindo que esses dois processos se afirmassem como modelos hegemônicos, deu aos Estados Unidos a possibilidade de pensar que chegara o momento de estender ao conjunto dos três continentes os benefícios de uma integração iniciada e que, julgavam, mostrara-se produtiva. Paralelamente, as próprias condições estratégico-militares em âmbito regional e mundial também favoreciam o governo norte-americano, uma vez - que uma das áreas de conflito político-ideológico mais intenso, a América Central, pacificara-se e o perigo comunista no continente, representado inicialmente por alguns países do Cone Sul e, posteriormente pela Nicarágua e Granada, parecia haver-se evaporado, permitindo aos Estados Unidos uma redefinição de suas prioridades.

A prioridade passava, assim, por integrar as três Américas e o Caribe, criando um mercado único de pouco mais de 800 milhões de habitantes, com um PIB de 11.220 bilhões de dólares, o que equivale a $40 \%$ do PIB mundial, e no qual os Estados Unidos detêm, aproximadamente, $80 \%$ do PIB do conjunto dos outros países da região. Nesse cálculo o Brasil, cuja economia é a maior do continente sul, pesa aproximadamente 17 vezes menos do que os Estados Unidos (SEAIN, 2000).

Um dos atrativos principais do projeto é a possibilidade de avançar em pontos que vão além dos que foram acordados no âmbito da Organização Mundial do Comércio (OMC). Entre esses pontos, é possível destacar o acesso irrestrito às licitações e contratos de fornecimento ao setor público dos demais países (ministérios, empresas estatais, etc.) e a interdição de quaisquer restrições à entrada de suas empresas no setor de serviços. Com efeito está 
previsto que corporações transnacionais possam adquirir direitos competitivos para fornecer amplo espetro de serviços em âmbito governamental e o direito de processar qualquer governo cujas medidas de ordem pública, ainda que legais, possam ser consideradas como prejudiciais a seus lucros imediatos ou potenciais. Dessa maneira a Alca, assim como o fizera o Nafta, facilitará a entrada pela porta dos fundos ao Acordo Multilateral de Investimentos.

Contudo, apesar desses privilégios, algumas dificuldades domésticas interpõem-se no caminho da realização da Alca, as mesmas que, como já vimos, haviam aparecido por ocasião da aprovação do Nafta. Elas têm como epicentro a oposição do Congresso norte-americano, que até o momento não concedeu ao presidente George W. Bush, apesar de todos seus esforços, a "autoridade de promoção comercial" que lhe permita operar em acordos comerciais com a rapidez e a liberdade necessárias. A recorrência na não aprovação desse mecanismo traduz o mesmo temor anterior de que, em face da competição de mão-de-obra mais barata - que no caso da Alca, se estenderia aos trabalhadores de, praticamente todos os países da América Latina - ocorresse um avanço no processo de flexibilização, de desproteção e de redução de empregos. Paralelamente, a possibilidade de acirramento da competição com empresas estrangeiras que, ao contrário das norte-americanas que sofrem as pressões de normas e de medidas de proteção relativas aos consumidores, ao meio ambiente, etc., se relacionam entre si livremente, constitui um fator a mais de preocupação.

A importância do mecanismo de "via rápida" está no fato de que, sem ele, os demais países do continente terão dificuldades em aceitar negociar o acordo proposto. $\mathrm{Na}$ realidade, a dinâmica do processo vai depender, em grande parte, do pleno envolvimento dos Estados Unidos, como diz Peter Hakim presidente do Inter-American Dialogue, para quem a obtenção do fast track tem o sentido de um convite (Hakim, The Washington Post, 18/04/01). A solução, contudo parece remota apesar do esforço do presidente George W. Bush em solucioná-la. Uma alternativa possível, e que já foi tentada, é a de negociar com os grupos contrários ao acordo a imposição de sanções a países que falharem na observação das normas de proteção aos trabalhadores e ao meio ambiente. Contudo, os governos latino-americanos, em que se inclui o do Brasil, não apóiam essa exigência, pois consideram que seria utilizada como elemento discriminatório nas relações comerciais entre os países centrais e os países em desenvolvimento. Por todas essas razões não é fácil discutir a Alca sem que isso pareça um puro exercício de futurologia, especialmente se acrescentarmos o fato de que os Estados Unidos, sócio maior da empreitada e seu maior idealizador, está passando por uma fase de recessão cujo alcance é ainda impreciso e pouco previsível.

Do lado dos países latino-americanos, para além das questões ideológicas que sempre coloriram as relações com os Estados Unidos, questões concretas dividem suas posições em relação à possível integração à Alca com efeito, a região latino-americana vive, no momento, uma sensação de insegurança econômica generalizada, cujas causas, provenientes de várias fontes, alimentam-se reciprocamente. Grande parte delas tem suas origens na vulnerabilidade da maioria de seus países em face da instabilidade financeira internacional, do reduzido crescimento econômico, e da crescente desigualdade e exclusão social decorrentes da perversa distribuição de renda, da ruptura da tênue rede de proteção social, da existência de um desemprego estrutural, todos fatores que tendem a se acentuar à medida que cresce, acima de qualquer outra alternativa, o compromisso de seus governos com as forças do mercado.

$\mathrm{Na}$ realidade, um dos problemas centrais que cerca o acordo de constituição da Área de Livre Comércio das Américas, desde o ponto de vista latino-americano, é a profunda assimetria econômica que separa os países da região entre si e entre eles e os Estados Unidos. Os números citados são suficientes para mostrar as diferenças no tamanho das economias que estão presentes no espaço territorial que se pretende integrar, no qual convivem a grande potência mundial com potências médias regionais e sub-regionais e países pequenos com economias frágeis ou em plena recessão e com pouco ou nenhum poder de negociação em âmbito internacional. De fato, se se comparar a região das Américas com outras regiões no momento que iniciam seu processo de integração, vê-se que, tomando como exemplo a "Europa dos 12", a relação entre o PNB médio de sua principal economia e a média das demais era de 3,1 vezes, proporção mais ou menos similar à dos outros esquemas de integração, como o Pacto Andino, Mercado Comum do Caribe, Mercado Comum Centro Americano e Nafta. No que se refere à Alca, a proporção alcança 23 vezes (Abreu, 1997).

De qualquer modo é preciso levar em conta, quando pensamos em um possível acordo de integração das Américas, que as relações entre países e grupos de países latino-americanos com os Estados Unidos sempre tiveram e terão uma agenda bilateral extensa, abrangendo, parale- 
lamente, interesses conflitantes e metas convergentes. No caso específico da Alca, a estratégia negociadora estará marcada pela dicotomia entre os atrativos de um acesso potencial ao mercado e à tecnologia de uma grande potência e os riscos de destruição da capacidade produtiva doméstica e regional (Tavares de Araújo, 1998).

Apesar dessa ambivalência, em que convivem esperanças por parte de setores que defendem o projeto Alca como alternativa prioritária, e temores e desconfianças de parte de outros setores que visualizam custos políticos e sociais graves, a integração comercial hemisférica é vista, quase pela maioria dos governantes da região, como um destino inexorável, não só por considerarem que o governo dos Estados Unidos se empenhará de todas as formas para que a rota já iniciada não se interrompa, em virtude do desenvolvimento linear do processo de globalização que estáse dando em todo o planeta.

Por outro lado, em face dessa perspectiva, avaliada como um horizonte próximo, um consenso parece formar-se na América Latina: o da necessidade de que os processos de integração sub-regionais em andamento aprofundem-se e de que desenvolvam entre si relações de maior densidade e operacionalidade. No que se refere especificamente ao Brasil, o compromisso com o Mercosul continua prioridade, embora, muitas vezes, o diálogo entre seus sócios tenha-se transformado em monólogo. Não se pode esquecer que seus dois maiores sócios, Brasil e Argentina, encontram-se com suas economias em crise, suas relações recíprocas muitas vezes turvadas, enfrentando problemas cuja solução não se descortina com facilidade. Mesmo assim, o Mercosul ainda representa uma aposta que se acredita que possa dar certo e um fator importante de legitimidade para as negociações internacionais, merecendo, portanto, que os esforços para sua continuidade sejam intensificados.

De qualquer maneira, não se pode desconhecer o fato de que o Mercosul está diante de um impasse que compromete sua continuidade, e que tem como epicentro a crise argentina, que se irradia por todos os demais sócios do bloco, gerando um fracionamento em suas posições, até aqui conjuntas, e fazendo com que alguns deles se mostrem tentados a seguir caminhos individuais como forma de sair da crise e de melhor integrar-se à economia hemisférica e mundial.

Com efeito, diante da Alca, as opiniões e os argumentos não apontam todos na mesma direção. Como já antecipamos, o Brasil, oficialmente, aspira a somar o peso dos quatro países na negociação e mostra-se como o mais forte opositor às práticas protecionistas dos Estados Unidos.
Já, no que se refere à Argentina, considerando as declarações de seu ex-ministro da Fazenda Domingo Cavallo, o governo considera que seria mais vantajoso para o país estabelecer relações comerciais diretas com os Estados Unidos do que conduzir as negociações desde Brasília. Acrescenta, contudo, que todas as alternativas devem ser utilizadas, incluindo-se a multilateral que envolve o Mercosul (Financial Times, 19/07/2001). Contudo, apesar de declarações e posições, no mínimo, ambivalentes, o governo argentino, na última Reunião de Cúpula em Quebec, assim como os do Paraguai e Uruguai, que também em outros momentos mostraram-se reticentes em relação à permanência do Mercosul, afirmaram não querer abandonar seu próprio projeto de integração sub-regional.

No que se refere a países fora do Mercosul, as posições também variam, como um dos exemplos o Chile, país associado e não seu membro pleno, que negocia bilateralmente com os Estados Unidos um acordo de livre-comércio, argumentando que, se os Estados Unidos não concordarem em fazê-lo, sendo o Chile um país de economia aberta e de tarifas baixas (8\%), será difícil explicar aos demais países da região seu compromisso real na abertura dos mercados (discurso de Ricardo Lagos na Câmara de Comércio dos Estados Unidos em abril de 2001). E ainda, a posição mais radical em favor da Alca dos países da América Central que, com suas economias já de fato na órbita dos Estados Unidos, consideram que têm mais a ganhar do que a perder nessa parceria. Na realidade, podendo ser quase equiparados ao México - primeiro parceiro comercial dos Estados Unidos -, Costa Rica, Honduras, Nicarágua, El Salvador e Panamá exportam mais de $70 \%$ para o mercado americano, e um de seus países, El Salvador, assim como o Equador, na região andina, já estabeleceram uma "santa aliança" com o dólar, ao mesmo tempo em que outros países da região também planejam fazê-lo. Correndo por fora, a Venezuela de Hugo Chavez tem mostrado uma posição crítica em relação ao documento assinado na Cúpula de Quebec, assumindo-se, retoricamente, como o mais novo representante do antiimperialismo norte-americano na América Latina (Le Monde, 20/04/01).

Voltando, com mais pormenores, a examinar a posição do Brasil, vê-se que a orientação de seu governo é a de aprofundar e fazer avançar o Mercosul e, desde esse patamar, negociar ponto por ponto cada item do novo regime hemisférico, em especial a questão da abertura dos mercados norte-americanos. O discurso diplomático brasileiro confirma essa posição e, mesmo, a radicaliza. Em 
diferentes ocasiões - discursos, entrevistas coletivas com jornalistas estrangeiros, palestras, etc. - o ministro das Relações Exteriores, Celso Lafer afirma: "O Mercosul é um destino para o Brasil, a Alca apenas uma hipótese", imagem que tem sido utilizada pelo próprio Presidente Fernando Henrique Cardoso. E continuando a desenvolver esse tipo de lógica: "A Alca é uma opção para o Brasil. Portanto não deve ser encarada com resignação, mas sim como um empreendimento que valerá a pena na medida em que for congruente com o projeto de desenvolvimento do país" (Lafer, 2001). Na realidade, essa posição aponta para questões substantivas que, segundo o governo brasileiro, são prévias a qualquer entendimento, e inegociáveis, como o corte dos subsídios na agricultura, a eliminação das barreiras não-tarifárias e modificações na legislação antidumping, mecanismos considerados como uma forma de protecionismo. Segundo ainda o ministro Celso Lafer, $60 \%$ das exportações brasileiras para os Estados Unidos defrontam-se com esse tipo de barreiras, seja na forma de medidas antidumping para o aço, seja de direitos compensatórios para o suco de laranja, seja de medidas sanitárias que restringem a exportação de carnes. "Não se trata apenas de uma negociação sobre tarifas, tratase de uma negociação de acesso a mercados", enfatiza (Lafer, 2001).

Com base nessa posição, o governo brasileiro, assumindo o compromisso com o que considera "o seu destino", tem-se empenhado em retomar as relações bilaterias com a Argentina, abaladas pelas medidas unilaterais tomadas por esse país. Na realidade a Argentina, ao abrir seus mercados a terceiros países na tentativa de resolver separadamente os graves problemas econômicos que a afligem, rompe, na prática, com a união aduaneira do Mercosul, revertendo o processo a uma fase anterior. $\mathrm{O}$ presente conflito com a Argentina, aparentemente já contornado, é especialmente sério, pois explicita publicamente percepções e interesses discordantes entre os dois maiores sócios do Mercosul, que pode ser interpretado como um mau sinal para os demais sócios plenos ou potenciais, enfraquecendo uma possível estratégia conjunta.

Mesmo com todo o empenho do Brasil e do fato de que as posições discordantes de seus sócios terem voltado a confluir na direção de um mesmo objetivo, o Mercosul na formação de um mercado comum - parece estar mortalmente ferido, muitos acreditando que possa retroceder em seus objetivos e tornar-se apenas um acordo intra-regional de abertura comercial. Se isso se concretizar, dificilmente poderá continuar a ser o único conjunto de paí- ses da região suscetível de se fazer ouvir, efetivamente, nas negociações perante os Estados Unidos.

Quanto a opinião da sociedade brasileira sobre os temas Mercosul e Alca, está longe de ser consensual sobretudo dos setores que, por diferentes razões, a eles estão ligados, como economistas, políticos, intelectuais, empresários, trabalhadores. De forma bastante impressionista, já que não há pesquisas sistemáticas sobre o tema, poderse-ia dizer que, de um lado, situam-se os que concordam com a estratégia do governo brasileiro por considerarem que a Alca, sendo um destino praticamente inevitável, poderá, se bem negociada, trazer benefícios para o Brasil e para toda a América Latina. Nesse caso, pensam que a consolidação do Mercosul constitui um recurso de poder essencial. De outro lado, há os que consideram que os custos de uma integração profundamente assimétrica do ponto de vista econômico e com uma enorme diferença de poder entre a potência que lidera o processo e os demais sócios e que, ao mesmo tempo, carece de redes de proteção capazes de neutralizar esses desequilíbrios, é totalmente incompatível com um projeto de desenvolvimento brasileiro e latino-americano. Os que assim pensam, apostam no avanço do Mercosul como a melhor solução a curto, médio e longo prazo para sair-se da crise, empurrando a solução hemisférica, se é que ela vai-se concretizar, para um horizonte sem prazo definido. Há ainda uma terceira vertente, os que, por negarem a importância do Mercosul ou sua viabilidade, não lamentam sua morte que consideram anunciada e apostam no ambicioso futuro próximo hemisférico que se descortina para todos os latino-americanos e brasileiros. No que se refere a esta última posição, uma pesquisa realizada no Conselho Empresarial da América Latina por Amâncio Jorge de Oliveira, no âmbito do Núcleo de Pesquisa em Relações Internacionais da USP, revela que uma maioria acima de $50 \%$ dos empresários considera que a Alca trará mudanças positivas para o País, e que esta proporção tende a subir (Estado de S.Paulo, 14/03/01).

Concluindo como síntese da posição do governo brasileiro e de boa parte da sociedade - economistas de modo geral, acadêmicos, intelectuais, lideranças políticas de diversas facções -, poder-se-ia dizer que a estratégia que mais conviria ao País seria o estabelecimento de relações comerciais plurais, incluindo diferentes blocos e regiões, e uma maior participação do Brasil nas instâncias internacionais. Essa estratégia, em que se privilegia a consolidação e aprofundamento do Mercosul, só poderia ser compatível com a Alca se viesse acompanhada de ações paralelas, ar- 
ticuladas entre si e simultâneas que, construídas ao longo do tempo, permitissem aproveitar todas as possibilidades econômicas do País derivadas de sua dimensão continental, da amplidão potencial de seu mercado, de uma estrutura industrial desenvolvida e de uma diversificação significativa conforme investimentos estrangeiros e fluxos internacionais (Coutinho, 1998).

No caso específico do Mercosul, cujo avanço daria ao Brasil e aos demais países-membros uma unidade de propostas e objetivos em face da Alca, é necessário, mais do que nunca, que os conflitos que inevitavelmente surjam em seu âmbito não congelem sua agenda, como os que têm ocorrido entre Brasil e Argentina, em que atritos comerciais mal resolvidos e posições tomadas individualmente vêm produzindo, além da queda do comércio entre eles, a percepção de que o Mercosul esgotou-se.

\section{REFERÊNCIAS BIBLIOGRÁFICAS}

ABREU, M. "O Brasil e a Alca: interesses e alternativas". In: REIS VELLOSO (org.). Desafios de um país em transformação. Rio de Janeiro, J. Editora, 1997.

BONILLA, A. "Percepciones de la amenaza a la seguridad nacional de los países andinos: regionalización del conflito colombiano y narcotráfico". Trabalho apresentado no Grupo de Trabalho de Relações Internacionais, do Conselho Latino-Americano de Ciências Sociais (Clacso), no âmbito do Seminário Internacional coordenado pelo Clacso e pelo Instituto de Relações Internacionais (IRI) da PUC-Rio. Rio de Janeiro, 24-27 de agosto, 2001, p.1-19.

BOTTARY, M. e SWENARCHUCK, M. "Nafta's investor rights: a corporate dream, a citizen nightmare". Multinational Monitor. Washington, v.22, April 2001.

CAMARGO, S. "Economia e política na ordem mundial contemporânea". Contexto Internacional. Rio de Janeiro, Instituto de Relações Internacionais da PUC-Rio, v.19, n.1, jan.-jun. 1997, p.7-39.

CEPAL. Notas da CEPAL, número especial, maio 1999.

CLARKSON, S. "Apples and oranges. Prospects for the comparative analysis of the EU and Nafta as Continental Systems". EUI Working Paper RSC., Itália. European University Institute, Badia Fiesolana, 2000.

COUTINHO, L. "A área de livre comércio das Américas - Riscos e oportunidades da integração continental assimétrica e acelerada". Trabalho apresentado no Seminário organizado pelo Instituto de Pesquisa de Relações Internacionais, Fundação Alexandre Gusmão, Ministério de Relações Exteriores. Rio de Janeiro, 6 jan. 1998.

FRITSCH, W. "Integración Economica: conviene la discriminación comercial?" In: BOUZAS, R. e LUSTIG, N. (org.). Liberalización comercial e integración regional. De Nafta a Mercosur. Buenos Aires, Grupo Editor Latinoamericano, 1992, p.37-53.

GARCIA, M.A. "Alca: riscos e oportunidades para o Brasil". Trabalho apresentado no Seminário organizado pelo Instituto de
Pesquisa de Relações Internacionais, Fundação Alexandre Gusmão, Ministério de Relações Exteriores. Rio de Janeiro, 6 jan. 1998.

GREIDER, W. "Sovereign corporations". The Nation, New York, v.272, April 30, 2001.

HAKIM, P. "La iniciativa para las Américas: que quiere Washington?". BOUZAS, R. e LESTING, N. (org.). Liberalización comercial e integración regional. De Nafta a Mercosur. Buenos Aires, Grupo Editor Latinoamericano, 1992, p.23-35.

"The Uneasy Americas". Foreign Affairs. Nova York, Council on Foreign Relations, v.80, n.2, mar.-abr. 2001, p.46-61.

HURREL, A. "O ressurgimento do regionalismo na política mundial". Contexto Internacional. Rio de Janeiro, Instituto de Relações Internacionais da PUC-Rio, v.17, n.1, jan.-jun. 1995, p.23-59.

KLEIN, E. e TOKMAN, V. "La estratificación social bajo tensión en la era de la globalización". Revista da Cepal, n.72, dez. 2000.

LAFER, C. "Alca: futuro". Discurso feito no Seminário: O continente americano e o futuro das integrações regionais. São Paulo, Memorial da América Latina, 04/04/2001.

LUSTIG, N. "La estrategia de apertura economica de México y el acuerdo de libre comércio de América del Norte”. In: BOUZAS, R. e LUSTIG, N. (org.). Liberalización Comercial e Integración Regional. De Nafta a Mercosur. Buenos Aires, Grupo Editor Latinoamericano, 1992, p.55-86.

MARSHALL, D.D. "Nafta/FTAA and the new ariculations in the Americas: Seizing structural opportunities". The World Quartely. Londres, v.19, n.4, 1998, p.673-700.

MITTELMAN, J.H. "Alternative Globalization". Trabalho apresentado no Seminário Internacional coordenado pelo Conselho LatinoAmericano de Ciências Sociais e pelo Instituto de Relações Internacionais da PUC-Rio. Rio de Janeiro, 24/27 ago. 2001.

MORRIS, S.D. e SMITH, J.P. "What a difference a crisis makes: Nafta, Mexico and the United States". Latin American Perspectives. River Side, v.28, may 2001.

NAISBAITT, J. Paradoxo global: quanto maior a economia mundial, mais poderosos são os seus protagonistas menores: nações, empresas e indivíduos. Rio de Janeiro, Ed. Campus, 1994 (Tradução de Ivo Korytowski).

SEAIN. Secretaria de Assuntos Internacionais. Indicadores da economia mundial. Ministério do Planejamento, Orçamento e Gestão. Brasília, n.11, dez. 2000.

SHOCH, J. “Contesting globalization: organized labor, Nafta, and 1997 and 1998 fast track fights". Politicas \& Society, Stoneham, v.28, mar. 2000.

TAVARES DE ARAÚJO, J. "Alca: riscos e oportunidades para o Brasil". Trabalho apresentado no Seminário coordenado pelo Instituto de Pesquisa de Relações Internacionais, Fundação Alexandre Gusmão, Ministério de Educação. Rio de Janeiro, 08/05/1998.

WILLIAM, G. "Sovereign Corporations". The Nation, Nova York, v.272, abr. 2001.

Sonia de Camargo: Professora e Diretora do Instituto de Relações Internacionais da PUC-RJ (scamargo@rdc.puc-rio.br). 